\title{
GAIA Level 2 Neonatal Death in an Extremely Preterm Live Birth
}

National Cancer Institute

\section{Source}

National Cancer Institute. GAIA Level 2 Neonatal Death in an Extremely Preterm Live

Birth. NCI Thesaurus. Code C127973.

GAIA Level 2 Neonatal Death in an Extremely Preterm Live Birth is defined by three criteria: first, the infant must be live born; second, at least one of the following requirements must be met: a) Gestational age greater than or equal to 22 and less than 28 weeks (where the GA level of certainty is either level one or level two) OR b) Birth weight greater than or equal to $500 \mathrm{~g}$ but less than $1000 \mathrm{~g}$; third, the death of the infant within the first 28 days of life must be documented. 